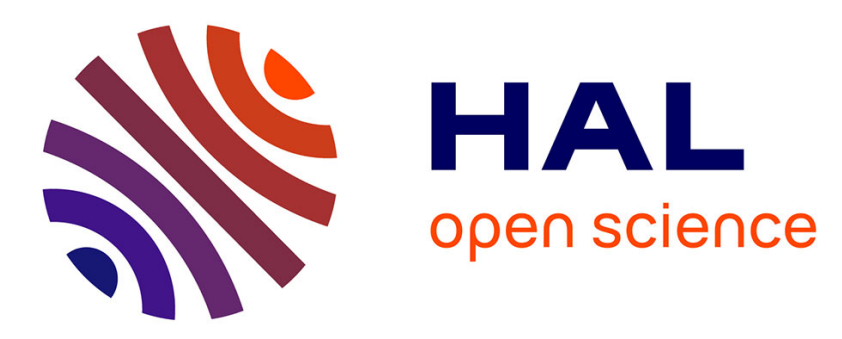

\title{
Highly filled polystyrene-laponite nanocomposites prepared by emulsion polymerization
}

Riccardo Ruggerone, Christopher C. J. G. Plummer, Norma Negrete Herrera, Elodie Bourgeat-Lami, Jan-Anders J.-A. E. Manson

\section{- To cite this version:}

Riccardo Ruggerone, Christopher C. J. G. Plummer, Norma Negrete Herrera, Elodie BourgeatLami, Jan-Anders J.-A. E. Manson. Highly filled polystyrene-laponite nanocomposites prepared by emulsion polymerization. European Polymer Journal, 2009, 45 (3), pp.621-629. 10.1016/j.eurpolymj.2008.12.032 . hal-00724904

\section{HAL Id: hal-00724904 \\ https://hal.science/hal-00724904}

Submitted on 8 Oct 2021

HAL is a multi-disciplinary open access archive for the deposit and dissemination of scientific research documents, whether they are published or not. The documents may come from teaching and research institutions in France or abroad, or from public or private research centers.
L'archive ouverte pluridisciplinaire HAL, est destinée au dépôt et à la diffusion de documents scientifiques de niveau recherche, publiés ou non, émanant des établissements d'enseignement et de recherche français ou étrangers, des laboratoires publics ou privés. 


\section{Highly filled polystyrene-laponite nanocomposites prepared by emulsion polymerization}

\section{Riccardo Ruggerone ${ }^{\mathrm{a}}$, Christopher J.G. Plummer ${ }^{\mathrm{a}}$, Norma Negrete Herrera ${ }^{\mathrm{b}}$, Elodie Bourgeat-Lami ${ }^{\mathrm{b}}$, Jan-Anders E. Månson ${ }^{\mathrm{a}, *}$ \\ a Laboratoire de Technologie des Composites et Polymères (LTC), Ecole Polytechnique Fédérale de Lausanne (EPFL), Station 12, CH-1015 Lausanne, Switzerland \\ ${ }^{\mathrm{b}}$ Chimie, Catalyse, Polymère, Procédé, C2P2/LCPP, UMR 5265 CNRS/CPE/UCBL, Bât. 308F, BP 2077-43, Bd. Du 11 Nov. 1918, 69616 Villeurbanne Cedex, France}

\section{A R T I C L E I N F O}

Article history:

Received 19 November 2008

Received in revised form 18 December 2008

Accepted 20 December 2008

Available online $\mathrm{xxxx}$

\section{Keywords:}

Polystyrene

Laponite

Nanocomposites

Mechanical properties

Emulsion polymerization

\section{Introduction}

Remarkable mechanical property improvements have been reported in polymer nanocomposites, but the effect of filler size and the role of the high specific interfacial area associated with nanofillers remain unclear [1-4]. In polymer/clay nanocomposites, maximum reinforcement is generally obtained with exfoliated rather than intercalated structures [5,6]. Stiffness reinforcement is already apparent at low clay contents [7-9], so that further increases in concentration might be expected to lead to even more marked effects [2,10-13]. However, clay contents are typically limited to 5-10 wt\% [13-15] owing to difficulties in obtaining adequate dispersions and/or the high melt viscosity of the nanocomposites and their precursors [16]. Polystyrene (PS)/clay nanocomposites have been prepared by melt blending [12,17-20], bulk in situ polymerization

\footnotetext{
* Corresponding author. Fax: +41021 6935880.

E-mail address: jan-anders.manson@epfl.ch (J.-A.E. Månson).
}

[9,21-23] and emulsion polymerization [14,24-26]. In this work, PS/synthetic laponite clay nanocomposites were obtained by an improved emulsion process, in which the interactions between the laponite and the PS are reinforced by modifying the laponite surface with a macromonomer. Such use of coupling agents has been described previously for a range of materials and preparation techniques [27-29]. Here, the styrene radicals react with the functionalized laponite as shown previously for polymer/silica nanocomposites [26,30,31]. This leads to a colloidal dispersion of PS particles with laponite platelets attached to their surfaces, which may be used to prepare PS films with laponite contents of up to at least $20 \mathrm{wt} \%$. The morphology of these films and the effect of the laponite on their stiffness and strength are discussed in the light of micromechanical models and fractography.

\section{Experimental section}

The characteristics of the emulsions are given in Table 1. The laponite (Laponite RD, Rockwood Additives Ltd. UK) 
Table 1

Formulations and characteristics of the emulsions.

\begin{tabular}{|c|c|c|c|c|c|c|}
\hline Latex & Laponite content $(\mathrm{g} / \mathrm{L})$ & SDS content $(\mathrm{g} / \mathrm{L})$ & Laponite/monomer (wt\%) & Solids content (\%) & Conversion (\%) & $D_{p}(\mathrm{~nm})$ \\
\hline LO & 0 & 2 & 0 & 16.6 & 97.8 & 82 \\
\hline L5 & 10 & 2 & 5 & 17.5 & 99.2 & 86 \\
\hline L10 & 20 & 2 & 10 & 17.5 & 94.1 & 78 \\
\hline L20 & 40 & 2 & 20 & 18.1 & 89.1 & 72 \\
\hline
\end{tabular}

was dispersed in water with a peptizing agent (sodium pyrophosphate, Aldrich, $10 \%$ by weight of laponite) and a surfactant (sodium dodecyl sulphate (SDS), Acros Organics) and stirred for 1-2 h. 5\% macromonomer (poly(ethylene oxide) 1000 monomethyl ether methacrylate, Polysciences) by weight of laponite was added to promote attachment of the laponite to the PS [26,30,31]. The functionalized laponite suspension was introduced to a reactor and stirred under $\mathrm{N}_{2}$. After degassing, styrene (Aldrich, $300 \mathrm{~g} / \mathrm{L}$ ) and the initiator (2,2' azobis(cyanopentanoic acid), Wako Chemicals, $0,5 \%$ with respect to the monomer) were added to the suspension and polymerization allowed to proceed at $70{ }^{\circ} \mathrm{C}$ for $4 \mathrm{~h}$. Latexes containing $0 \mathrm{wt} \%$ laponite (L0), and approximately $5 \mathrm{wt} \%$ laponite ( $\mathrm{L} 5$ ), $10 \mathrm{wt} \%$ laponite (L10) and $20 \mathrm{wt} \%$ laponite (L20) with respect to the PS were prepared in this way. The particle diameters $\left(D_{p}\right)$ from dynamic light scattering (DLS) are given in Table 1. Solid films were obtained by compression molding the dried latexes (Fontijne Holland Press) at $160{ }^{\circ} \mathrm{C}$ to give transparent films of $0.3 \mathrm{~mm}$ in thickness. The weight average PS molar mass, $M_{w}$, was determined by gel permeation chromatography (GPC) to be $1.2 \times 10^{6} \mathrm{~g} / \mathrm{mol}$. The polydispersity was 3.23 .

To evaluate PS particle size distributions by scanning electron microscopy (SEM, Philips XL30), the latexes were spin coated onto a steel substrate at $1460 \mathrm{rev} / \mathrm{min}$ for $180 \mathrm{~s}$ and then carbon coated. The distribution of the laponite in the latexes was investigated by transmission electron microscopy (TEM, Philips CM20), by either (i) spin coating the diluted latex (20 times in water) onto carbon covered copper grids or (ii) embedding the latex in a water soluble resin (Nanoplast FB 101 kit, Polysciences Inc., ratio 2 parts of resin to 1 part of latex by weight, following the supplier's protocol); the resulting solid blocks were then sectioned with an ultramicrotome (Reichert-Jung Ultracut E) equipped with a diamond knife (Diatome). The size distribution of the as-received laponite particles was determined by TEM of a $0.1 \mathrm{wt} \%$ aqueous suspension deposited on a carbon covered copper TEM grid and stained with ammonium molybdate and bacitracine. The film morphologies were investigated by TEM of microtomed sections and X-ray diffraction (XRD) (Siemens Kristalloflex 805, Cu $\mathrm{K}_{\alpha}, \lambda=1.54 \AA$ ).

Dynamic mechanical analysis (DMA, TA instruments Q100)) temperature scans were made on $10 \times 20 \times$ $0.3 \mathrm{~mm}^{3}$ rectangular specimens cut from the films $(10$ $\mathrm{K} / \mathrm{min}, 1 \mathrm{~Hz}$ ). Differential scanning calorimetry (DSC, TA instruments Q100) was used to measure the glass transition temperature, $T_{\mathrm{g}}(5 \mathrm{mg}, 15 \mathrm{~K} / \mathrm{min})$. Tensile tests were carried out at room temperature on double edge-notched tensile (DENT) specimens cut from the films as shown in Fig. 1, using a miniature tensile test machine (Minimat, Polymer Labs) at a speed of $0.1 \mathrm{~mm} / \mathrm{min}$. The ligament

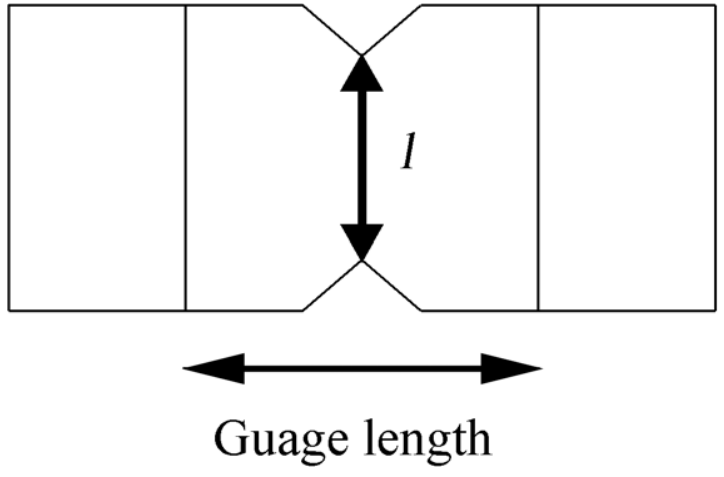

Fig. 1. Double edge-notched tensile (DENT) specimen geometry used for the tensile tests.

length, $l$ (see Fig. 1) was varied from 2 to $5 \mathrm{~mm}$ following the essential work of fracture (EWF)-based protocol for the study of thin film fracture properties [32].

\section{Results}

The mean PS particle diameter was determined by SEM to be $80 \pm 30 \mathrm{~nm}$ for all the latexes, consistent with the DLS results (Table 1 ). The form of the as-received laponite platelets was irregular, and a mean effective particle diameter of $54 \mathrm{~nm}$ was therefore defined from measurements of the mean minimum and maximum lateral dimensions of 80 individual particles determined by TEM. Figs. 2 and 3 show TEM images of latexes L10 and L20 obtained using the embedding technique, and of the dried latexes (LO, L10 and L20), respectively. Although laponite platelets were occasionally encountered in the aqueous phase of the latex, they showed the expected strong tendency to adhere to the surface of the PS particles.

Given that the laponite platelets are extensively bound to the polymer particle surfaces, they are expected to remain at, or close to the original inter-particle boundaries during the compaction step, implying a cellular arrangement of the laponite particles to persist in the absence of extensive matrix flow. Fig. 4 shows TEM images of sections from pressed films prepared from latexes L5, L10 and L20. The dispersion of the laponite in the PS matrix was relatively uniform at the scale of these micrographs. However, as shown in Fig. 4(d-f), the laponite was only partially exfoliated, even at the lowest concentrations (L5). This was confirmed by XRD, all the nanocomposite films showing a diffraction peak at $2 \Theta$ of approximately $6^{\circ}$, i.e. a layer spacing, $d_{001}$, of about $1.48 \mathrm{~nm}$, which compares with about $1 \mathrm{~nm}$ for the unmodified laponite, and $1.32 \mathrm{~nm}$ for 

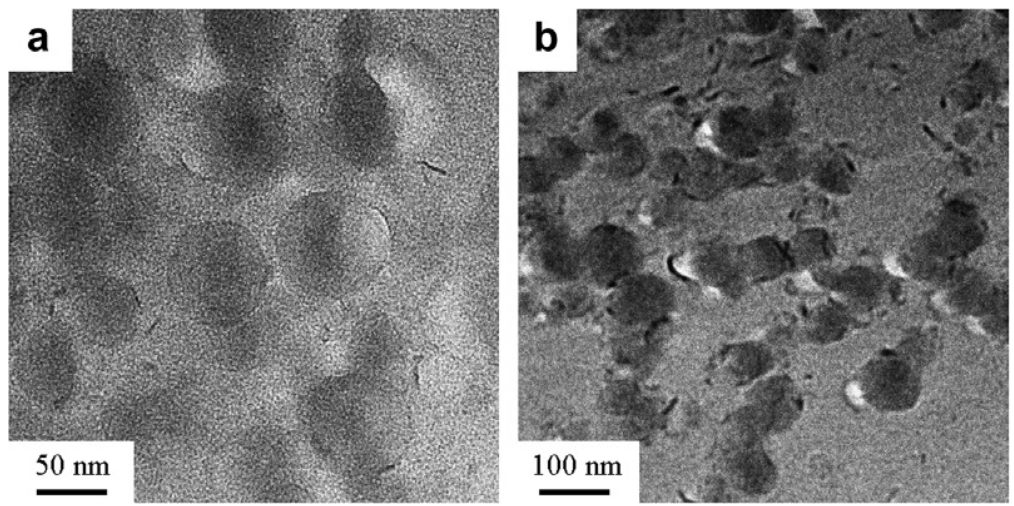

Fig. 2. TEM images of thin sections of (a) L10 and (b) L20 latexes embedded in melamine resin. Laponite particles are indicated by the arrows.
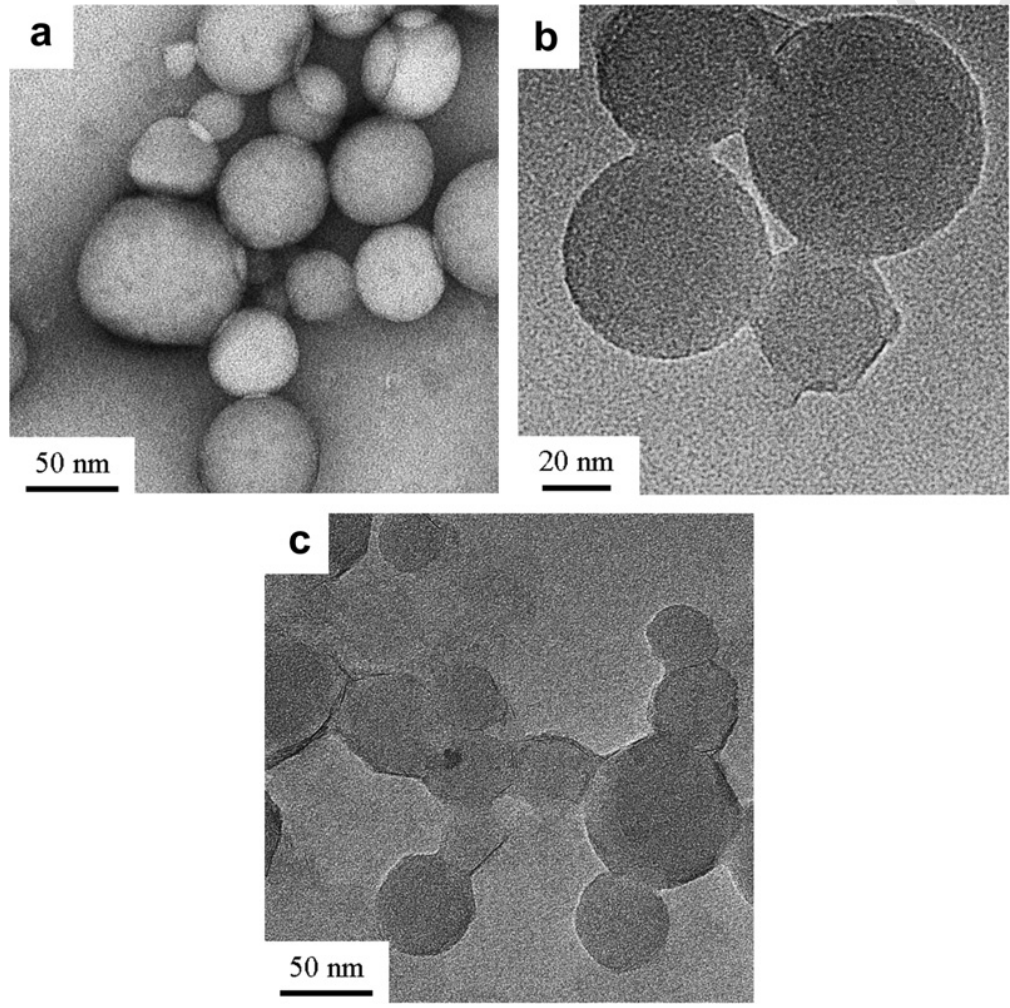

Fig. 3. TEM images of latexes deposited on carbon films by spin coating: (a) L0; (b) L10; (c), L20.

the laponite treated with the macromonomer, regardless of the surfactant and laponite concentration, suggesting significant intercalation by the PS. The lower magnification TEM images confirmed the cellular arrangement of the laponite particles in L10 and L20 (Fig. 4(b-c)), with a cell size corresponding closely to the original latex particle diameter.

As shown in Fig. 5, changes in the storage modulus, $E^{\prime}$, were observed in both the glassy and rubbery states on laponite addition, along with small shifts in $T_{\alpha}$, the temperature corresponding to the peak in $\tan \delta$ associated with the $\alpha$ transition (Table 2). However, although $E^{\prime}$ increased strongly and monotonically with laponite content in the rubbery state, the films containing $5 \mathrm{wt} \%$ laponite (L5) showed higher $E^{\prime}$ in the glassy state than both the unmodified latex (LQ) and films containing higher laponite concentrations (L10 and L20). Moreover, $T_{\alpha}$ also showed the largest increase in the films prepared from L5. Consistent results were obtained by DSC, with the largest increase in $T_{\mathrm{g}}$ again being observed in the films prepared from L5 (Table 2).

Typical stress (force normalized with respect to the ligament cross-sectional area) displacement curves from DENT specimens with a ligament length of $3 \mathrm{~mm}$ are 

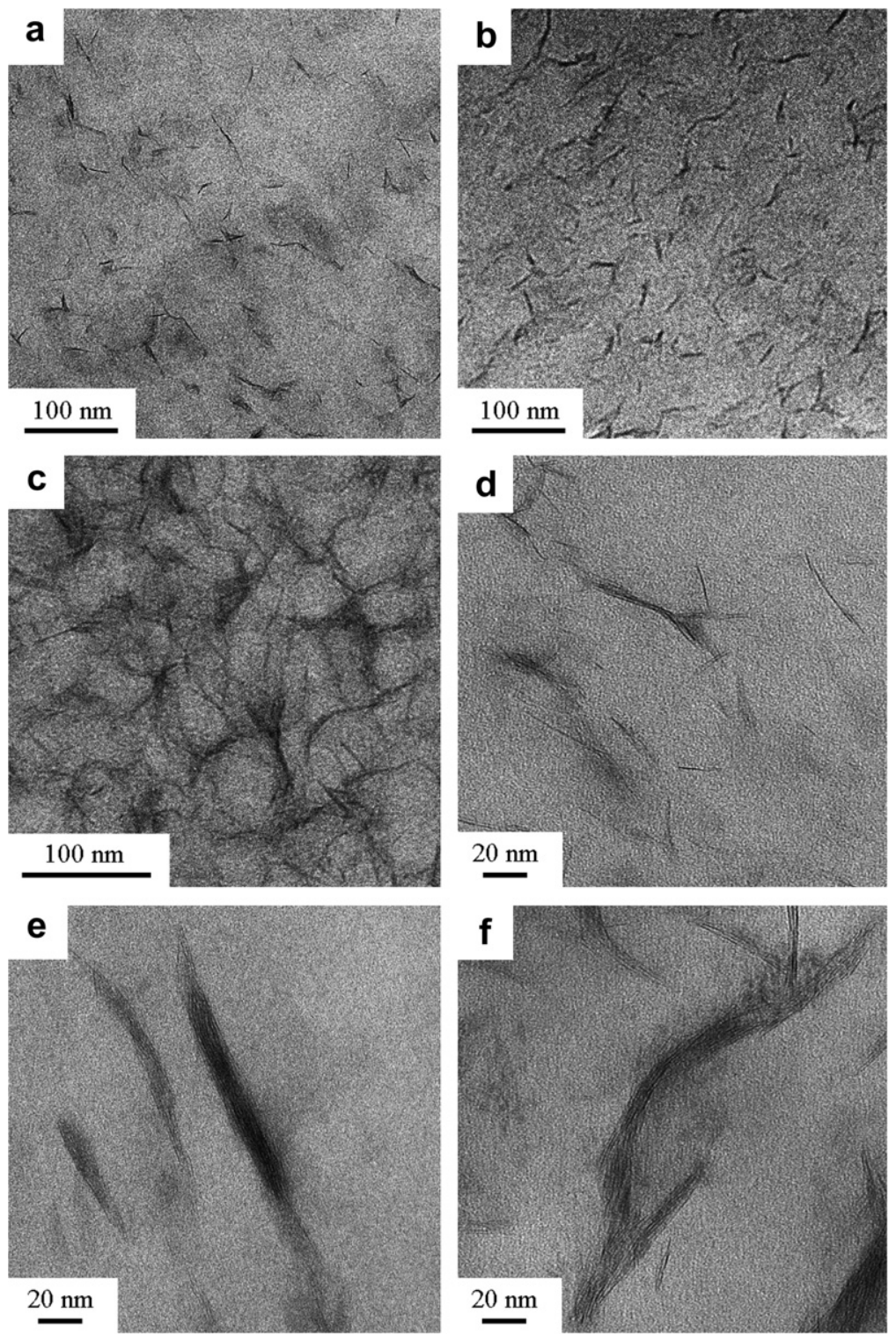

Fig. 4. TEM micrographs of thin sections from consolidated films prepared from (a) L5; (b) L10 and (c) L20. (d-f) show higher magnification images of the films in $(a-c)$, respectively.

shown in Fig. 6. Failure was brittle in all cases, and full section yielding was not observed prior to crack onset, invalidating the EWF approach. Moreover, the scatter in the data made it impossible to identify any systematic dependence of the effective tensile strength, defined as the maximum force divided by the ligament cross-sectional area, on $l$ and hence, for the purposes of comparison, results are given in Table 3 for the mean tensile strength for all $l$, the mean elongation at break (maximum total specimen strain) and the apparent stiffness (initial slope of the force normalized with respect to the ligament cross-sectional area vs. the total specimen strain). According to these definitions, films containing 10 and $20 \mathrm{wt} \%$ laponite (L10 and L20) showed reduced tensile strength and elongation at break compared with the unmodified films (LO), although their apparent stiffness increased. On the other hand, films containing $5 \mathrm{wt} \%$ laponite (L5) showed not only the highest stiffness, consistent with the DMA results, but also the highest tensile strength.

\section{Discussion}

Increases in stiffness on clay addition to styrenic polymers obtained using the synthetic techniques referred to in the introduction, with different types of clay and clay modification, have been widely reported [14,18,19,21,22,$24,25]$. Relatively small increases in $E^{\prime}$ in the glassy state in the presence of the clay coupled with very large increases in the rubbery state are also reported in many of 
a

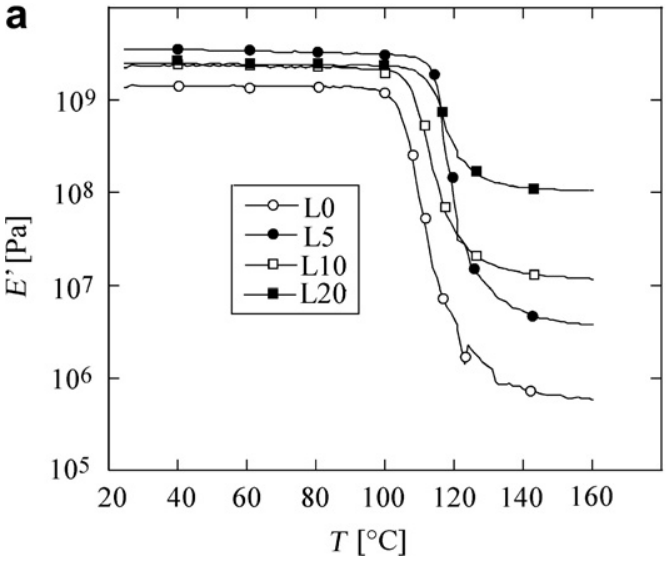

b

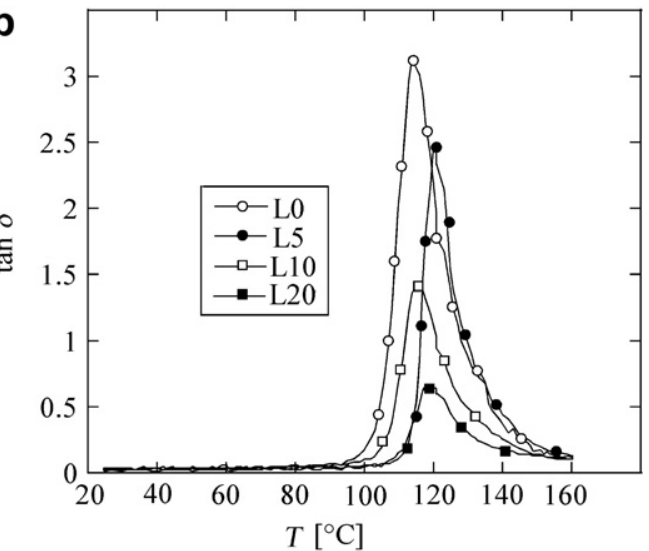

Fig. 5. (a) $E^{\prime}$ and (b) tan $\delta$ in consolidated films prepared from L0, L5, L10 and L20.

Table 2

$E^{\prime}$ in the glassy and rubbery state $\left(160^{\circ} \mathrm{C}\right)$ and transition temperatures for the consolidated films.

\begin{tabular}{lllll}
\hline Latex & $\begin{array}{l}E^{\prime} \text { (glassy state) } \\
(\mathrm{GPa})\end{array}$ & $\begin{array}{l}E^{\prime} \text { (rubbery state) } \\
(\mathrm{MPa})\end{array}$ & $\begin{array}{l}T_{\alpha} \\
\left({ }^{\circ} \mathrm{C}\right)\end{array}$ & $\begin{array}{l}T_{\mathrm{g}} \\
\left({ }^{\circ} \mathrm{C}\right)\end{array}$ \\
\hline L0 & 1.4 & 0.8 & 116 & 103 \\
L5 & 3.4 & 3.1 & 121 & 114 \\
L10 & 1.9 & 10.2 & 118 & 106 \\
L20 & 2.0 & 102 & 119 & 111 \\
\hline
\end{tabular}

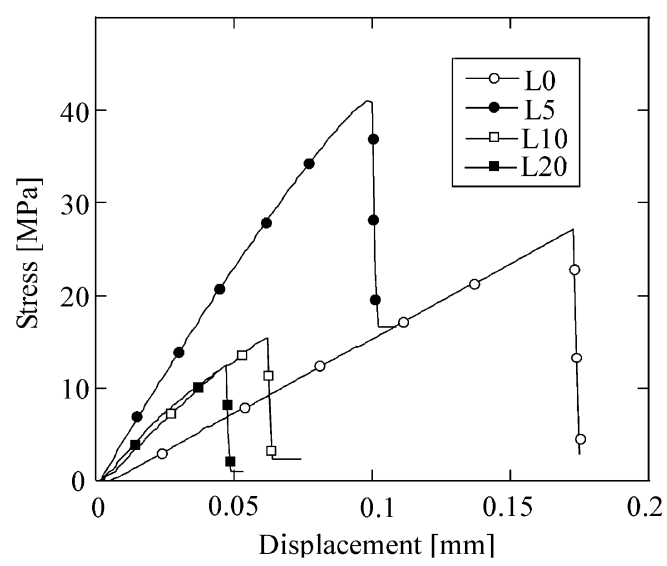

Fig. 6. Stress-displacement curves from tensile tests on DENT specimens from consolidated films prepared from L0, L5, L10 and L20 with a ligament length of $3 \mathrm{~mm}$.

these systems $[18,19,21,25]$. This general trend towards increased stiffness has been explained in terms of both classical mechanical reinforcement by the relatively rigid clay platelets, and restricted mobility in the polymer matrix, often associated with an interphase at the clay platelet surfaces and/or to chain confinement effect in the interlayer galleries of intercalated clay stacks $[14,15]$. However, quantitative explanations for the very different degrees of reinforcement in the glassy and rubbery states are generally lacking.
Table 3

Tensile properties of DENT specimens from the consolidated films.

\begin{tabular}{llll}
\hline Latex & $\begin{array}{l}\text { Tensile strength } \\
(\mathrm{MPa})\end{array}$ & $\begin{array}{l}\text { Elongation at break } \\
(\%)\end{array}$ & $\begin{array}{l}\text { Nominal stiffness } \\
(\mathrm{GPa})\end{array}$ \\
\hline L0 & $26 \pm 7$ & $2.54 \pm 0.73$ & $1.49 \pm 0.42$ \\
L5 & $42 \pm 13$ & $1.21 \pm 0.46$ & $3.55 \pm 1$ \\
L10 & $16 \pm 8$ & $0.83 \pm 0.32$ & $2.02 \pm 0.60$ \\
L20 & $12 \pm 5$ & $0.68 \pm 0.23$ & $1.98 \pm 0.62$ \\
\hline
\end{tabular}

The relationship between the clay content and $T_{\mathrm{g}}$ also remains unclear. In general, the higher the clay concentration, the higher $T_{\mathrm{g}},[14,21,24,33]$ but decreases in $T_{\mathrm{g}}$ have also been reported, which may result from a plasticizing effect, e.g. due to the presence of surfactants in the modified clays or reduced matrix molar masses $[22,25,34]$. In the present case, the effective surfactant content was constant throughout (see Table 1) and the molar masses were high, consistent with the observed increases in $T_{\mathrm{g}}$ with laponite content, which were therefore assumed to be essentially due to restricted mobility near the transition.

The observed storage moduli obtained from DMA were compared with values calculated using the Halpin-Tsai and Mori-Tanaka models and estimates of the morphological parameters associated with the laponite particles. Rather than consider single laponite platelets as the reinforcing elements, which is unrealistic in view of the TEM and XRD observations, the mean dimensions and aspect ratios (diameter/thickness) of the laponite aggregates were estimated from TEM micrographs for each type of composite film comprising images of 120 aggregates, assuming these to represent diametral sections. Mean aspect ratios of $21.77,6.45$ and 5.46 were determined in this way for L5, L10 and L20, respectively. A mean aggregate volume, $V_{\mathrm{aggr}}$, and the volume of polymer matrix per aggregate, $V_{\mathrm{aggr}}$, were also estimated as described elsewhere [35]. The aggregate volume fraction was determined from

$\phi=\frac{V_{\mathrm{aggr}}}{V_{\mathrm{aggr}}+V_{\mathrm{pol}}}$ 

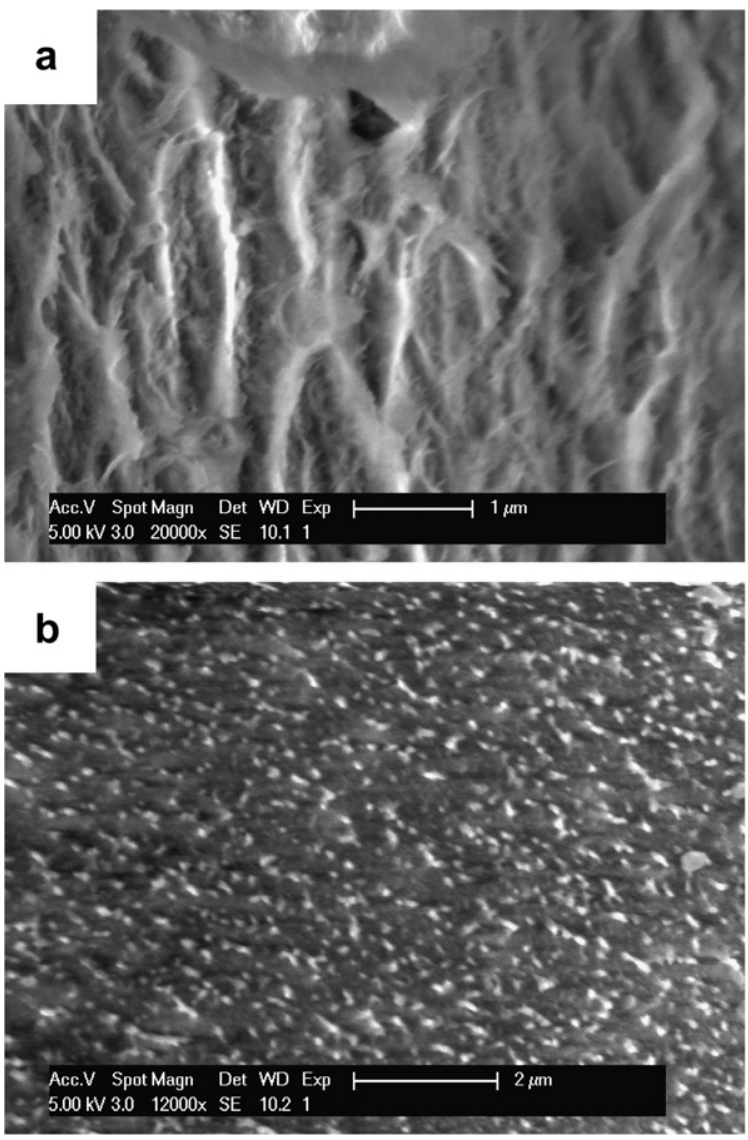

Fig. 7. SEM micrographs of the fracture surfaces from DENT specimens of (a) a consolidated film prepared from LO and (b) and a consolidated film prepared from L20.

The modulus of the laponite aggregates was calculated following Sheng et al. [36] assuming the properties of the polymer in the interlayer galleries to be isotropic and identical to those of the matrix. The Young's modulus of the laponite, $E_{f}$, was taken to be $178 \mathrm{GPa}$ and the Poisson's ratios of the laponite and the polymer were 0.15 and 0.33 , respectively [37-39]. The Halpin-Tsai equations $\wedge$

$$
E_{1}=E_{m}\left(\frac{1+\zeta \eta \phi}{1-\eta \phi}\right), \quad \hat{\text { with }} \zeta=2 \alpha, \quad \text { and } \quad \eta=\left(\frac{\frac{E_{f}}{E_{m}}-1}{\frac{E_{f}}{E_{m}}+\zeta}\right)
$$

where $E_{m}$ is the matrix modulus, were then used to evaluate the elastic modulus of the nanocomposites as follows: Eq. (2) gives the in-plane aggregate modulus, $E_{1}$, and the out-of-plane modulus, $E_{3}$, may be obtained by substituting $\zeta=2$ in Eq. (2). Assuming an isotropic orientation distribution for the aggregates, the overall modulus $E$ is then estimated to be $0.49 E_{1}+0.51 E_{3}$ [40]. The Mori-Tanaka model was applied using the simplified Hui-Shia formulation [41], assuming the same aggregate aspect ratio and composition as for the previous calculations. The resulting predictions for $E$ in the glassy state are shown in Fig. 8, indicating order of magnitude agreement with the data in this regime. Moreover, the model calculations reproduced qualitatively the peak in modulus at $5 \mathrm{wt} \%$ laponite, which was ascribed to the relatively high degree of exfoliation in this case, and hence the high effective particle aspect ratios.

At $T>T_{\mathrm{g}}$, simple geometrical models were inadequate, underestimating the reinforcing effect of $20 \mathrm{wt} \%$ laponite by about 2 orders of magnitude, as shown in Fig. 9 (the Poisson's ratio of the matrix was taken to be 0.48 in the rubbery state [42]). The large increases in the $E^{\prime}$ might in principle be accounted for by the presence of a filler or filler-polymer network [43-49]. The existence of a supramolecular structure has been inferred previously from rheological studies of PS/monmorillonite composites obtained by emulsion polymerization [46]. In the present case, rheological studies were inconclusive owing to the relatively high matrix molar mass, which made it difficult to access the terminal zone experimentally. However, as described in the results section, TEM provided some direct evidence of a cellular arrangement of the laponite aggregates arising from their tendency to adhere to the surfaces of the latex particles in the precursor suspensions. In the

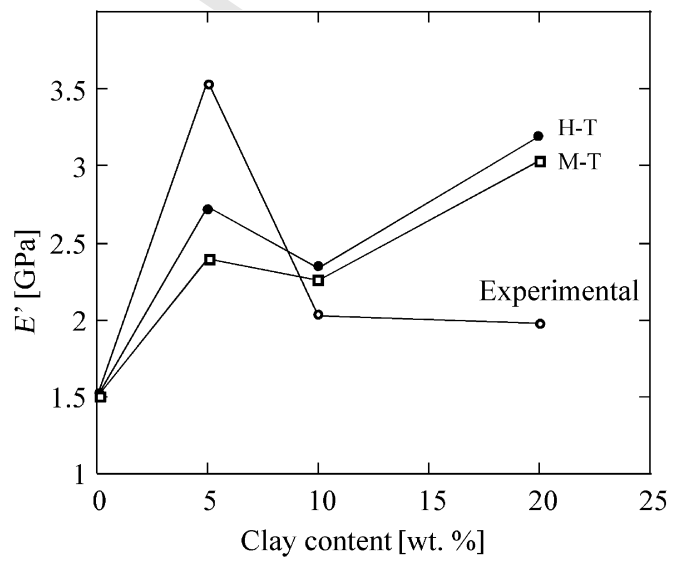

Fig. 8. Comparison of experimental $E^{\prime}$ at room temperature with values calculated from the Halpin-Tsai (H-T) and Mori-Tanaka (M-T) models.

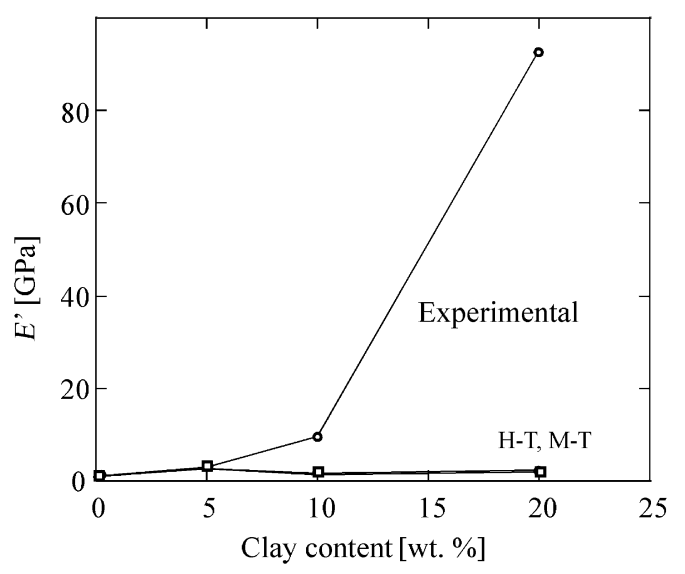

Fig. 9. Comparison of experimental $E^{\prime}$ at $160{ }^{\circ} \mathrm{C}$ with values calculated from the Halpin-Tsai (H-T) and Mori-Tanaka (M-T) models. 
dried latexes, the laponite may therefore be considered to form a more or less complete shell around the latex particles, depending on its concentration and dispersion. By considering a laponite platelet (or agglomerate) to be equivalent to a flexible disc of $54 \mathrm{~nm}$ in diameter, complete coverage may be shown to correspond to a uniform distribution of about 9 platelets per latex particle. Individual laponite platelets are approximately $1 \mathrm{~nm}$ thick, so taking the density of PS to be $1.05 \mathrm{~g} \mathrm{~cm}^{-3}$ and that of laponite to be $2.08 \mathrm{~g} \mathrm{~cm}^{-3}$, there would be roughly 3, 6 and 12 platelets per particle for latexes L5, L10 and L20, respectively, in the event of full exfoliation. Thus $\boldsymbol{n}_{\mathrm{n}}$ at the particle-particle interfaces in the films, which are shared by adjoining particles, an average of about 6, 12 and 24 platelets is predicted to be associated with each original particle. It follows that whereas a fully exfoliated morphology is at least possible in films cast from latex L5, the total interfacial area is insufficient to accommodate a single layer of laponite platelets in films cast from latexes L10 and L20, and stacking of the platelets is inevitable, regardless of the initial state of exfoliation of the laponite.

In practice, complete exfoliation was not achieved, even in the L5-based films, as shown by TEM and XRD, and the observed agglomerate sizes in all the films were greater than required by the above packing considerations, with number average thicknesses of 8.4 and $9.9 \mathrm{~nm}$ being estimated from TEM for L10 and L20, respectively, i.e. agglomerates of 6-7 laponite layyers, or an effective particle thicknes, of 6-7 nm. Under these conditions, full coverage of the latex particles is unlikely, and indeed it is not clear that percolation of inter-particle contacts was achieved at any concentration. The percolation threshold for contacts between (overlapping) discs placed randomly on a 2D surface corresponds to a surface coverage $\varphi_{c}=0.676$ and a total disc area per unit surface of 1.12 [50,52]. For an effective particle aspect ratio of $9(=54 / 6)$, the total volume fraction of laponite corresponding to percolation would be about $25 \%$, i.e. greater than the concentrations under consideration here. It is therefore proposed that the nanocomposites be modeled as a closed-cell PS/laponite foam whose wall thickness, $t$, is of the order of the mean aggregate thickness, and whose cell diameter, $D$, is equal to the latex particle diameter. All the laponite present in any given nanocomposite is assumed to be concentrated in the cell walls, and the cells are filled with pure PS matrix, which is taken to behave as an incompressible solid in the rubbery state, with modulus $E_{m}$. For $E>>E_{m}$, the overall stiffness is then approximated by

$E \approx\left(\frac{t}{D}\right)^{2}\left\{1+\left(\frac{t}{D}\right)^{2}\right\} E_{f}+O\left(E_{m}\right) \approx\left(\frac{t}{D}\right)^{2} E_{f}+E_{m}$

Q2 where $E_{f}$ is the modulus of the cell walls [52]. The HalpinTsai model was used to predict $E_{f}$, from the local concentration of laponite in the cell walls and assuming a homogeneous dispersion of the laponite platelets with $\alpha=54$ $(t=2.5,8.4$ and $9.9 \mathrm{~nm}$ for L5, L10 and L20, respectively, leading to laponite concentrations of approximately 27 , 17 and $30 \mathrm{vol} \%)$. However, if the matrix modulus in the cell walls is taken to be that of the unmodified PS in the rubbery state, i.e. $E_{m}=0.8 \mathrm{MPa}$ (see Table 2 ), $E$ is estimated

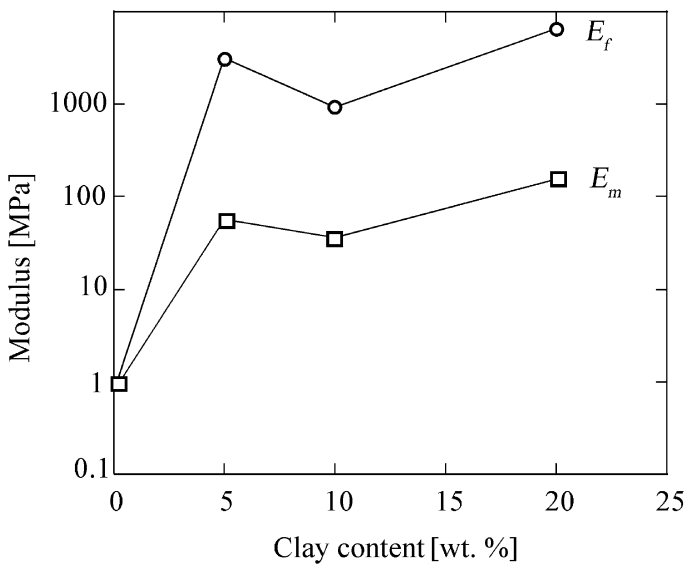

Fig. 10. Values of $E_{f}$ and $E_{m}$ required to fit the experimental data for the rubbery modulus via the foam model as described in the text.

to remain of the order of $E_{m}$ for all the overall laponite concentrations, consistent with Eq. (2), but clearly inconsistent with the data. On the other hand, although the small measured shifts in $T_{\mathrm{g}}$ suggested little influence of the laponite on the global matrix properties, this may not be true of the cell walls. Indeed, at 30 vol\% laponite (the estimated concentration in the cell walls for L20), the mean platelet spacing is inferred to be of the order of $2 \mathrm{~nm}$ locally, which is comparable with independent calorimetric estimates of the thickness of immobilized layers in semicrystalline polymers and polymer-clay nanocomposites in which there is a strong interaction between the matrix and the clay $[53,54]$. The effect of any such immobilization on the local matrix stiffness is difficult to quantify a priori, but it is possible to back-calculate the values of $E_{f}$ and the corresponding values of $E_{m}$ required to account for the experimental values of $E$ in terms of Eq. (3) for the different nanocomposites. As shown in Fig. 10, this implies the average local matrix modulus to increase by approximately 2 orders of magnitude in the cell walls, whilst remaining below its value for $T<T_{\mathrm{g}}$, which appears reasonable, given that the presence of an immobilized layer is not necessary to account for the elastic response below $T_{\mathrm{g}}$.

\subsection{Tensile strength}

As indicated in Table 3, addition of $5 \mathrm{wt} \%$ laponite resulted in a small increase in the tensile strength of the notched specimens, but there was a progressive reduction as the laponite content was raised further. The peak in fracture resistance at $5 \mathrm{wt} \%$ laponite was consistent with the trends in $E^{\prime}$ in the glassy state, and it was therefore inferred that exfoliation is also an important factor for the high strain properties. Previous observations of a decrease in elongation at break and the tensile strength with clay content in styrenic polymer-based nanocomposites, have been accounted for in terms of poor adhesion between the clay and the polymeric matrix $[14,17,19,23]$. It follows that where improvements in matrix clay adhesion have been achieved by suitable surface functionalization of the clay platelets, the tensile strength is increases in well-dispersed 
systems at low clay contents [21]. A possible explanation for the present non-monotonic behavior might therefore be weaknesses associated with the relatively large laponite agglomerates observed at high laponite contents. SEM images showed fibrillation during failure of the unmodified matrix (Fig. 7(a)), consistent with crazing and/or locally ductile behaviour, whereas a network of well defined "tufts" was visible at the fracture surfaces of the highly filled films (Fig. 7(b)). It was not possible to identify the locus of failure unambiguously from such images, but preliminary in situ observations by TEM of microdeformation in thin films prepared from the different nanocomposite have indicated the onset of failure in the nanocomposites with high laponite contents to be associated with the formation of localized deformation zones containing cavities with diameters comparable with those of the original PS latex particles [55]. Based on the foam model invoked in the previous section, it is inferred that the initial damage mechanism at high laponite contents is plastic growth of cavities within the PS-rich regions. Crack advance is then assumed to proceed by rupture of the intervening ligaments corresponding to the cell walls, accounting for the residues on the fracture surface visible in Fig. 7(b). The decrease in fracture resistance in L10 and L20 may be at least in part due to reduced plasticity in these ligaments with respect to that of unmodified PS. In the relatively highly exfoliated L5-based films, in which the cellular structure was less in evidence, crazing remained the dominant deformation mode, as in the pure PS matrix, so that the laponite was presumably able to act as a reinforcement e.g. by introducing local stress concentrations to the vicinity of the crack tip, resulting in delocalization of the crack-tip damage zone and increased energy dissipation.

\section{Conclusion}

An emulsion polymerization route has been used to obtain loadings of up to $20 \mathrm{wt} \%$ of well-dispersed laponite clay in solid PS films. DMA indicated the laponite to result in modest stiffness reinforcement for $T<T_{\mathrm{g}}$, whereas for $T>T_{\mathrm{g}}$, the stiffness reinforcement was significantly greater. The behavior in the rubbery state has been modeled assuming a continuous foam-like cellular arrangement of regions relatively rich in laponite particles, corresponding to the original particle surfaces. It is argued that the local matrix modulus in the vicinity of the laponite particles must be significantly higher than that of the PS, implying local restrictions on the matrix mobility. At high laponite contents, the local reduction in matrix mobility associated with the increases in rubbery modulus may also lead to decreased ductility, accounting for the observed decreases in fracture resistance. Future work will focus on the microdeformation mechanisms associated with to fracture at different laponite loadings, and the range of laponite contents will be extended to higher concentrations in order to provide better defined cellular morphologies and a basis for more detailed investigation of the foam model.

\section{Uncited reference}

Q1 [51].

\section{Acknowledgement}

This work was supported by the European Framework 6 Project NAPOLEON and technical support was provided the Centre Interdisciplinaire de Microscopie Electronique (CIME) of the EPFL.

\section{References}

[1] Cho J, Joshi MS, Sun CT. Effect of inclusion size on mechanical properties of polymeric composites with micro and nano particles. Compos Sci Tech 2006;66:1941-52.

[2] Reynaud E, Jouen T, Gautheir C, Vigier G, Varlet J. Nanofillers in polymeric matrix: a study on silica reinforced PA6. Polymer 2001;42:8759-68.

[3] Lazzeri A, Thio YS, Cohen RE. Volume strain measurements on $\mathrm{CaCO}_{3} /$ polypropylene particulate composites: the effect of particle size. J Appl Polym Sci 2004;91:925-35.

[4] Petrovic ZS, Javni I, Waddon A, Banhegyi G. Structure and properties of polyurethane-silica nanocomposites. J Appl Polym Sci 2000;76: 133-51.

[5] Luo JJ, Daniel IM. Characterization and modelling of the mechanical behaviour of polymer/clay nanocomposites. Compos Sci Tech 2003;63:1607-16.

[6] Hasegawa N, Kawasumi M, Kato M, Usuki A, Okada A. Preparation and mechanical properties of polypropylene-clay hybrids using a maleic anhydride modified polypropylene oligomers. J Appl Polym Sci 1998;67:87-92.

[7] Chang JH, An YU. Nanocomposites of polyurethane with various organoclays: thermomechanical properties, morphology and gas permeability. J Polym Sci B Polym Phys 2002;40:670-8.

[8] Wu CL, Zhang MQ, Rong MZ, Friedrich K. Tensile performance improvements of low nanoparticles filled-polypropylene composites. Compos Sci Tech 2002;62:1327-40.

[9] Tseng CR, Wu JY, Lee HY, Chang FC. Preparation and characterization of polystyrene-clay nanocomposites by free radical polymerization. J Appl Polym Sci 2002;85:1370-7.

[10] Vollenberg PHT, Heikens D. Particle size dependence of Young's modulus of filled polymers: 1. Preliminary experiments. Polymer 1989;30:1656-62.

[11] Chan CM, Wu J, Li JX, Cheung YK. Polypropylene/calcium carbonate nanocomposites. Polymer 2002;43:2981-92.

[12] Park CI, Park OO, Lim JG, Kim HJ. The fabrication of syndiotactic polystyrene/organophilic clay nanocomposites and their properties. Polymer 2001;42:7465-75.

[13] Tortora M, Gorrasi G, Vittoria V, Galli G, Ritrovati S, Chiellini E. Structural characterization and transport properties of organically modified monmorillonite/polyurethane nanocomposites. Polymer 2002;43:6147-57.

[14] Noh MW, Lee DC. Synthesis and characterization of polystyrene-clay nanocomposites by emulsion polymerization. Polym Bull 1999;42:619-26.

[15] Lee DC, Jang LW. Preparation and characterization of PMMA-clay hybrid composites by emulsion polymerization. J Appl Polym Sci 1996;61:1117-22.

[16] Alexandre M, Dubois P. Polymer-layered silicate nanocomposites: preparation, properties and uses of a new class of materials. Mater Sci Eng Reports 2000;28:1-63.

[17] Tanoue S, Utraki LA, Garcia-rejon A, Tatibouët J, Kamal MR. Melt compounding of different grades polystyrene with organoclays. Part3. Mechanical properties. Polym Eng Sci 2005;45:827-37.

[18] Bhiwankar NN, Weiss RA. Melt intercalation/exfoliation of polystyrene-sodium montmorillonite nanocomposites using sulfonated polystyrene ionomer compatibilizers. Polymer 2006;47: 6684-91.

[19] Sepher M, Utraki LA, Zheng XC, Wilkie CA. Polystyrene with macrointercalated organoclay. Part 2. Rheology and mechanical performance. Polymer 2005;46:11569-81.

[20] Burmistr MV, Sukhyy KM, Shilov VV, Pissis P, Spanoudaki A, Sukha IV, et al. Synthesis, structure, thermal and mechanical properties of nanocomposites based on linear polymers and layered silicates modified by polymeric quaternary ammonium salts (ionenes). Polymer 2005;46:12226-32.

[21] Uthirakumar P, Song MK, Nah C, Lee YS. Preparation and characterization of exfoliated polystyrene/clay nanocomposites using a cationic radical initiator-MMT hybrid. Eur Polym J 2005;41:211-7. 
[22] Fu X, Qutubuddin S. Synthesis of polystyrene-clay nanocomposites. Mater Lett 2000;42:12-5.

[23] Su S, Wilkie CA. Exfoliated poly(methyl methacrylate) and polystyrene nanocomposites occurs when the clay cation contains a vinyl monomer. J Polym Sci A Polymer Chem 2003;41:1124-35.

[24] Li H, Yu Y, Yang Y. Synthesis of exfoliated polystyrene/ montmorillonite nanocomposites by emulsion polymerization using a zwitterion as the clay modifier. Eur Polym J 2005;41: 2016-22.

[25] Kim YK, Choi YC, Wang KH, Chung IJ. Synthesis of polystyrene-Na MMT nanocomposites via emulsion polymerization. Chem Mater 2002;14:4990-5.

[26] Bourgeat-Lami E, Negrete-Herrera N, Putaux JL, Reculusa S, Ravaine $\mathrm{S}$, Duguet $\mathrm{E}$, in preparation..

[27] Negrete-Herrera N, Letoffe JM, Putaux JL, David L, Bourgeat-Lami E. Aqueous dispersion of silane-functionalized laponite clay platelets. A first step towards the elaboration of water-based polymer/clay nanocomposites. Langmuir 2004;20:1564-71.

[28] Vu YT, Mark JE, Pham LH, Engelhardt M. Clay nanolayer reinforcement of cis-1, 4-polyisoprene and epoxidized natural rubber. J Appl Polym Sci 2001;82:1391-403.

[29] Negrete-Herrera N, Putaux JL, David L, Bourgeat-Lami E. Polymer/ laponite composite colloids through emulsion polymerization: influence of the clay modification on particle morphology. Macromolecules 2006;39:9177-84.

[30] Furusawa F, Kimura Y, Tagawa T. Synthesis of composite polystyrene latices with silica particles in the core. J Colloid Interf Sci 1986:109:69-76.

[31] Reculusa S, Poncet-Legrand C, Ravaine S, Mingotaud C, Duguet E, Bourgeat-Lami E. Synthesis of raspberrylike silica/polystyrene materials. Chem Mater 2002;14:2354-9.

[32] Clutton E. In: Fracture mechanics testing methods for polymers adhesives and composites. ESIS publication 28, Elsevier Science LTD; 2001. p. 177.

[33] Bruzaud S, Grohens Y, Illinca S, Carpentier JF. Syndiotactic polystyrene/organoclay nanocomposites: synthesis via in situ coordination-insertion polymerization and preliminary characterization. Macromol Mater Eng 2005;290:1106-14.

[34] Xie X, Hwu JM, Jiang GJ, Buthelezi TM, Pan WP. A study of the effect of surfactants on the properties of polystyrene-montmorillonite nanocomposites. Polym Eng Sci 2003;43:214-22.

[35] Ciprari D, Jacob K, Tannenbaum R. Characterization of polymer nanocomposites interphase and its impact on mechanical properties. Macromolecules 2006;39:6565-73.

[36] Sheng N, Boyce MC, Parks DM, Rutledge GC, Abes JI, Cohen RE. Multiscale micromechanical modelling of polymer/clay nanocomposites and the effective clay particle. Polymer 2004;45: 487-506.

[37] Fornes TD, Paul DR. Modeling properties of nylon6/clay nanocomposites using composite theory. Polymer 2003;44: 4993-5013.
[38] Liopo VA, Metsik MS, Orekov AV. The relation between macromodulus and micro-modulus of elasticity of mica crystals. Russ Phys J 1973;16:1478-9.

[39] Rinde JA. Poisson's ratio of rigid plastic foams. J Appl Polym Sci 1970;14:1913-26.

[40] Plummer CJG, Rodlert M, Bucaille JL, Grünbauer HJM, Månson JAE. Correlating the rheological and mechanical response of polyurethane nanocomposites containing hyperbranched polymer. Polymer 2005;46:6543-53.

[41] Hui CY, Shia D. Simple formulae for the effective moduli of unidirectional aligned composites. Polym Eng Sci 1998;38:774-82.

[42] Hutcheson SA, McKenna GB. Nanosphere embedding into polymer surfaces: a viscoelastic contact mechanics analysis. Phys Rev Lett 2005;94:076103.

[43] Dalmas F, Chazeau L, Gauthier C, Cavaillé JY, Dendievel R. Large deformation behavior of flexible nanofiber filled polymer nanocomposites. Polymer 2006;47:2802-12.

[44] Chabert E, Bonert M, Bourgeat-Lami E, Cavaillé JY, Dendievel R, Gauthier C, et al. Filler-filler interactions and viscoelastic behaviour of polymer nanocomposites. Mater Sci Eng A 2004;381:320-30.

[45] Zhong Y, Zhu Z, Wang SQ. Synthesis and rheological properties of polystyrene/layered silicate nanocomposite. Polymer 2005;46:3006-13.

[46] Park BJ, Kim TH, Choi HJ, Lee JH. Emulsion polymerized polystyrene/ monmorillonite nancomposites and its viscoelastic characteristics. J Macromol Sci B 2007;46:341-54.

[47] Sohn JI, Lee CH, Lim ST, Kim TH, Choi HJ, Jhon MS. Viscoelasticity and relaxation characteristics of polystyrene clay nanocomposites. J Mater Sci 2003;38:1849-52.

[48] Rodlert M, Plummer CJG, Grünbauer HJM, Månson JAE. Hyperbranched polymer/clay nanocomposites. Adv Eng Mater 2004;6:715-9.

[49] Rodlert M, Plummer CJG, Leterrier Y, Månson JAE. Rheological behavior of hyperbranched polymer/montorillonite clay naocomposites. J Rheol 2004;48:1049-66.

[50] Quintanilla JA, Ziff RM. Asymmetry in the percolation thresholds of fully penetrable discs with two different radii. Phys Rev E 2007; 76:051115.

[51] Xia W, Thorpe MF. Percolation properties of random ellipses. Phys Rev A 1988;38:2650-6.

[52] Warner M, Edwards SF. A scaling approach to elasticity and flow in solid foams. Europhys Lett 1988;5:623-8.

[53] Sargsyan A, Tonoyan A, Davtyan S, Schick C. The amount of immobilized polymer in PMMA $\mathrm{SIO}_{2}$ nanocomposites determined from calorimetric data. Eur Polym J 2007;43:3113-27.

[54] Schick C, Wurm A, Mohammed A. Formation and disappearance of the rigid amorphous fraction in semicrystalline polymers revealed from frequency dependent heat capacity. Therm Acta 2003;396:119-32.

[55] Ruggerone R, Plummer CJG, Negrete-Herrera N, Bourgeat-Lami E, Månson JAE. Eng Fract Mech, submitted for publication.. 